\title{
MASTER
}

\section{REDESIGN OF BENDIX VARIABLES DATA SYSTEM}

Earl W. Morris

Bendix Corporation, Kansas City, Missouri 64141

Several mnsiderations, when ageimilatcd into an overall review, prompted the decision to redesign the Bendix Variables Data System. Briefly, these are:

1. Recent surveys indicate a data growth rate by FY1982 of approximately ten (10) times current annual volume.

2. Requirements to edit, store, retrieve, and analyze data in exponential notation format.

3. Requirements to edit, store, retrieve, and analyze digitized waveform data.

4. Need to develop real-time maintenance capabilities for the system's control files.

5. Improvement of on-line data retrieval and analysis capability for Bendix and Design Agency users.

6. The off-line (batch) portion of the redesigned system must be capable of (I) selective and concurrent file updates, and (2) self-generation and scheduling of the tasks to be executed.

A two-phased implementation schedule is planned. On-line maintenance of the system's control files is scheduled for June, 1978, and the balance in January, 1979. 


\section{DISCLAIMER}

This report was prepared as an account of work sponsored by an agency of the United States Government. Neither the United States Government nor any agency Thereof, nor any of their employees, makes any warranty, express or implied, or assumes any legal liability or responsibility for the accuracy, completeness, or usefulness of any information, apparatus, product, or process disclosed, or represents that its use would not infringe privately owned rights. Reference herein to any specific commercial product, process, or service by trade name, trademark, manufacturer, or otherwise does not necessarily constitute or imply its endorsement, recommendation, or favoring by the United States Government or any agency thereof. The views and opinions of authors expressed herein do not necessarily state or reflect those of the United States Government or any agency thereof. 


\section{DISCLAIMER}

Portions of this document may be illegible in electronic image products. Images are produced from the best available original document. 
Although the abstract, as published, was a synopsis for our overall redesign effort, this paper will focus on only those aspects relating to our planned support for digitized waveform data.

The reader should be familiar with the contents of the paper "A Proposed Format For the Recording and Transmission of Digital Transient Signals in GEISHA" by D. A. Young and J. R. Yoder, SLA; as this paper will frequently reference formats and other considerations contained therein.

our current planning for digital signal processing is based on the premise that the above proposed formats will become a part of the GEISHA language.

\section{Product Testers}

Due tó the volume of data generated, we recommend that testers, generáting digitized waveforms for inclusion in our data system, be hard-wired into the Mezzanine Data Acquisition System. This DAS requires tester output to be in card GEISHA format. In the 
case of multiplexed waveforms (i.e., a "D" record contains more than one waveform), the tester output must be card GEISHA format. This restriction is necessary when considering the extraórdinary length of the output record if recorded in any other format.

Data Eaiting

During the edit phase, multiplexed waveforms will be decommutated and passed to the file maintenance program as single waveforms.

To facilitate editing, a new data type, "W", will be utilized to denote that a non-standard ID contains waveform data. 
EXHIBIT A

MASTER FILE RECORD DESCRIPTION

VARIABLES DATA RECORD

VADA-RCD.

02 SEQ-ALL.

03 SEQ-FA.

04 PN PICTUIRF $X(8)$.

$04 . M F G-C D$ PICTURE $\dot{X}(4)$.

04 TST-CD PICTURE $X(2)$.

04 SRC-CD. PICTURE $X$.

04 LOT-NO.

$\begin{array}{lll}05 & \text { LOT-N } & \text { PICTURE } X(4) . \\ 05 & \text { LOT-SFX }\end{array}$

04 SER-N

PICTURE. $X(8)$.

03 TST-TM.

04 TST-DT.

04 TM-O-DAY

PICTURE $X(6)$.

03 RCD -TY

03 FILLER

PICTURE $X(4)$.

PICTURE $\times$.

PICTURE $X(6)$.

02 OTHR-HDR-FLDS.

03 TSTR $-N$.

04 TSTR

04 TSTR-SN

0.1 TSTR-TY

$03 D T-C D$

$03 . X M I T N-C N T L$

03 BXPN-SFX

03 SPN-SFX

03 PRD-SPEC.

04 PS-PFX

04 PS-SFX

PICTURE $X(8)$.

PICTURE $X(6)$.

PICTURE $X(6)$.

PICTURE $X(6)$.

PICTURE $X$.

PICTURE $X X X$.

PICTURE $X X$.

PICTURE XXX.

PICTURE XXX.

03. NOMNCL

PICTURE $X(11)$.

PICTURE $9(4)$.

PICTURE $X$.

PICTURE S9(5) COMPUTATIONAL-3.

PICTURE $X$.

PICTURE S9(5) COMPUTATIONAL-3.

PICTURE $59(5)$. COMPUTATIONAL -3 .

-PICTURE S9(3) COMPUTATIONAL - 3 .

02 TST-CNT
02 TST-INFO OCCURS 500 TIMES DEPENDING ON TST-CNT.

03 TST-DATA.

04 TST-N PICTURE $X(6)$.

04 TST-TYPE PICTURE $X$.

04 TST-RDNG PICTURE $X(8)$.

04 DISP-CD

04 XMITN-SW

PICTURE $X$.

PICTURE $X$. 


\section{EXHIBIT B}

MASTER FILE RECORD DESCRIPTION

WAVEFORM DATA RECORD

WVFRM-RCD.

02 SEQ-ALL.

03 SEQ-FA.

04 PN

$04 M F G-C D$

04 TST-CD

04 SRC-CD

04 LOT-NO.

PICTURE $\times(8)$.

PICTURE $X(4)$.

-PICTURE X(2).

PICTURE $X$.

PICTURE $X(4)$.

PICTURE $X$.

04 SER-N

PICTURE $X(8)$.

03 TST-TM.

04 TST-DT

04 TM-O-DAY

03 RCD-TY

PICTURE $X(6)$.

PICTURE $X(4)$.

02 OTHR-HDR-FLDS.

0.3 TSTR-N.

04 TSTR

04 TSTR-SN

PICTURE $X$.

PICTURE $X(8)$

PICTURE $X(6)$.

PICTURE $\times(6)$.

03 DT-CD

03 XMITN-CNTL

03 BXPN-SFX

03 SPN-SFX

PICTURE $\times(6)$.

PICTURE $\dot{x}$.

PICTURE XXX.

03 PRD-SPEC.

PICTURE $X X$.

04 PS -PFX

$04 \cdot$ PS-SFX

PICTURE $X X X$.

PICTURE $X X X$.

03 NOMCL

PICTURE $X(11)$.

02 ATT-NO

$0.2 \quad A T T-S W$

02 CRE-DT

02 XMITN-IND

02 XMITN-DT

02 REV-DT

02 N-FILLER

$02 W-C N T$

02

WVFRM-INFO

03 WVFRM-DATA.

04 ELEMNT-TYPE 'PICTURE $X$.

04 ELEMNT-DATA PICTURE $X(3)$. 


\section{Data Storage}

As indicated in the referenced paper by D. A. Young and J. R. Yoder! SLA, a "D" record may contain data elements other than amplitude samples. In order to store these data in context with the amplitude samples, we will employ the following code schema:

\begin{tabular}{|c|c|c|}
\hline Data Element & Standard-ID & Element-ID \\
\hline Starting or Fiducial Time & $\mathrm{TF}$ & 1 \\
\hline Sampling Interval & DT & 2 \\
\hline Scaling Multiplier & $\therefore A M$ & 3 \\
\hline Amplitude Sample & NONE & 4 . \\
\hline Element Continuation & Not. Applicable & 0 \\
\hline
\end{tabular}

This schema allows maximum utilization of the "ocCuRs" areas in the Wa'veform Data Record (Exhibit B). Amplitude samples will be stored in packed decimal format while all other data elements, and all element identifiers will be stored in display format.

Examples:

Scaling Multiplier "AMb6.'2358.07". would occupy three (3) occurs areas as follows:

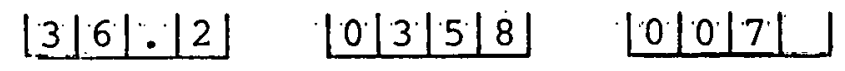

Amplitude Sample "00010" would occupy only one (1) occurs area as follows:

$\lfloor 4+0100110$ 
Starting or Fiducial Time, Sampling Interval, and. Scaling Multiplier entries may be expressed in exponential notation format which will require four (4) occurs areas to record. Amplitude samples will always be expressed in five (5) integers and will require only one (1) occurs area to record.

The tcot cquipment designer should use to tollowing formula to calculate the number of occurs areas required to record his waveförm:

(Number of occurences of Starting or Fiducial Time output $x$ 4): + (Number of occurences of Sampling Interval outputs $x$ 4)

+ (Number of occurences of Scaling Multiplier outputs x 4)

= (Maximum "occurs areas" required to store the waveform)

Maximum number of "occurs" should not exceed 2,250.

It should be noted that the waveform elements are stored in exactly the same sequence as they appeared in the "D" record; or as decommutated, in the case of multiplexed waveforms.

Retrieval and Analysis

No definition exists as yet in this area.

Data Transmission to Design Agencies

Data will be extracted from our files and recoded in the " $D$ " record format for transmission. We anticipate the need for further 
negotiations in this area especially concerning automated correction capabilities:

Summary

As stated previously, our planning is based primarily upon the contents of the paper "A Proposed Format For the Recording and Transmissiull uf Diyttal Translent stgnals in GL'LHA" by

D. A. Young and J. R. Yoder, SLA.

If the contents of that paper change drasticaliy, or if the Design Agency cannot support implementation on a timely basis, then our support efforts will be seriously impaired.

Mr. Morris is a Systems Analyst, Staff at Bendix Kansas City. He is currently the project leader for the Redesign of the Bendix Variables Data System; and in-house consultant for Structured Programming Techniques. Past assignments include the original Bendix Variables Data System, Tool Cost Monitor Systems, and Specification Exception Release (SXR) Reporting system. Mr. Morris, a 1955 graduate of Southeast Missouri State, University with a B.S. in Accounting, has been associated with Bendix Kansas City since 1957. 